easily transfer Str. pyogenes to her hands and clothing. Herein lies the danger of transfer of infection either to a mother or to another infant.

Enough evidence was found in the outbreaks described above for a plea to be made to include swabbing of the umbilicus of the infant in any routine investigation of puerperal infection.

It cannot be stressed too often that swabbing should always precede treatment. In the first paper on the use of antibiotics in haemolytic streptococcal puerperal infection, James (1945) showed how quickly a vaginal swab became free from haemolytic streptococci when an infected patient was treated with penicillin. The whole pattern of an outbreak may be obscured by treatment. Antibiotic therapy need not be delayed more than the few minutes needed to carry out the swabbing. When the results are presented by the bacteriologist, the clinician may either confirm or modify his treatment. These same principles certainly apply to the swabbing of the neonatal umbilicus.

\section{Neonatal Infection}

The possibility of haemolytic streptococci playing a pathogenic role in the infart has not so far been considered. In our experience these organisms did not appear to give rise to any signs on the cord stump itself. Indeed, there is very little in contemporary obstetric literature describing clinical signs of any sort of infection of the cord stump. Older writers, however, made some comment on inflammation of the navel. Mauriceau (1683) mentioned inflammation and ulceration of the navel, and so does Jane Sharp (1725). James Hamilton (1813), in a section on diseases of infants in his father's textbook of obstetrics, described an "erysipelatous inflammation" which sometimes "begins at the belly." Trousseau (1844) described a disastrous outbreak of fatal erysipelas of the abdominal wall in newborn infants. In nearly every case the umbilical area was involved. Meynet (1857) described similar epidemics of both erysipelas and gangrene of the umbilicus in newborn infants. The last two disasters occurred in or near the decade 1850 60 which Colebrook (1955) has described as "perhaps the blackest period in all the story of hospital infection." Nowadays manifest umbilical sepsis in the newborn appears to be a rarity.

It seems possible that the haemolytic streptococci could gain access to the peritoneum via the umbilical cord and cause streptococcal peritonitis. This presumably does not often occur, because none of the 14 infants followed up during the second outbreak was clinically ill. However, one infant in the first outbreak who was acutely ill recovered after treatment with chlortetracycline. Swabs from this infant were unfortunately not taken before treatment was started. This infant may have been suffering from streptococcal peritonitis, but in the absence of laboratory examination it would have been very difficult to establish the diagnosis.

In a comprehensive review of peritonitis in the neonatal period Rickham (1955) states that peritonitis is a "not uncommon cause of disease and death in the neonatal period." He mentions streptococcal peritonitis as a blood-stream infection. Gubern Salisachs (1951), in discussing two cases of streptococcal peritonitis in the newborn, suggests the umbilicus as a portal of entry for the haemolytic streptococcus.

Cullen wrote in 1916 " that in every instance of illness in a newborn infant it should always be the rule to inspect and if necessary reinspect the navel." One might add that this inspection should include a bacteriological examination.

\section{Summary and Conclusions}

Two outbreaks of group A streptococcal infection in maternity units are described.

In each outbreak infants in the nursery were found to be carrying Str. pyogenes on the umbilicus.

Carriage of Str. pyogenes was found to continue up to eight weeks.
A general investigation into the bacteriology of the infant's umbilicus is described.

The umbilicus of the newborn infant might provide the means of spread of streptococcal infection to its own mother, to other mothers and infants in the same maternity unit, to midwives, and in domiciliary practice to members of the household.

Bacteriological examination of the umbilical swab may help to solve some epidemiological problems in puerperal sepsis.

We wish to thank Mr. R. M. Williams for permission to make use of the clinical material at Glasfryn Maternity Home; Dr. Rees Evans, the Medical Officer of Health for Carmarthenshire, for his co-operation; and the hospital and domiciliary midwives and the health visitors whose diligent swabbing meant so much in this work.

REFERENCES

Cullen, T S. (1916). Embryology, Anatomy, and Diseases of the Umbilicus. Saunders Philadelphia and London.

Colebrook, L. (1946). J. Obstet. Gynaec. Brit. Emp., 53, 114. Colebrook, (1955) Lancet, 885 .

Cruickshank, R., and Godber, G. E. (1939). Ibid., 1, 741.

Edmunds, P. N.' Elias-Jones, T. F., Forfar, J. O., and Baif, C. L. (1955). British Medical Journal, 1 990 .

Gibson, J., and Calman, R. M. (1953). Lancet, 1, 320.

Groson, J., and Caiman, R. M. (1953). Lancet, 1, 320. plaint: with Hints for the Treatment of the Principal Diseases plaint: with Hints for the Treatment of the Principal

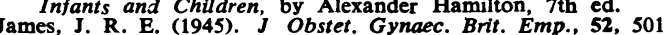

Kenny, M , and Barber, M. (1944). British Medical Journal, 1, 809.

Knox, R., and Marmion, B. P. (1945). Monthly Bull. Minist. Hith (Lond.) 4, 249.

Mauriceau, F. (1683). Diseases of Women, translated by Hugh Chamberien 2nd ed., p. 392. London.

Meynet, C. H. P. (1857). Thèse, No. 156. Paris.

Phillips, M. H. (1938). Brittsh Medical Journal, 1, 1.

Rickham, P. P. (1955). Arch. Dis. Childh., 30, 23.

Salisachs, L. Gubern (1951). Acta pediát. esp., 9, 27.

Sharp, Jane (1725). The Compleat Midwife's Companion, p. 233. London. Troussenu, M. (1844). J. Med. Chir., 2, 1.

\section{SURGERY OF PERSISTENT DUCTUS ARTERIOSUS*}

BY

ROWAN NICKS, O.B.E., Ch.M., F.R.C.S.

AND

P. J. MOLLOY, M.B., Ch.B.

From the Cardio-Thoracic Surgical Unit, Green Lane Hospital, Auckland, New Zealand

Since the first successful ligation of a persistent ductus arteriosus by Gross and Hubbard (1939) fired the imagination of surgeons to explore the new world of civilian cardiac surgery, there have been reservations and difference of medical opinion in regard to the treatment of individual cases. With the rapid development of safe surgery the practical issue became defined, for the hazard of conservative management was generally conceded to be greater than the risk of ligation or suture, and the frequent occurrence of the malformation required the formulation of a basic policy which need be altered only under special circumstances.

\section{Present Series}

The series surveyed, referred from all parts of New Zealand, with a population of two million people and catered for by a free medical specialist service, represents the experience of those entrusted with the major part of this work in the period under consideration. Of 155 cases of persistent ductus arteriosus examined at the Cardiosurgical Clinic in Auckland between 1948 and February, 1955, 138 received surgical treatment, the policy being to advise operation, when

*Based on a paper delivered at the General Scientific Meeting, Royal Australasian College of Surgeons, Sydney, Australia, August, 1955. 
convenient, between the ages of 5 and 25 years. Patients under 5 were treated only after careful assessment because of an increased anaesthetic and post-operative risk, and those over 25 only if they had symptoms and wished the operation performed. The ages of the 155 patients (43 male, 112 female) are shown in Table $I$.

TABLE I.-Age Incidence

TABLE I.-Age Incidence
\begin{tabular}{ll|c|c|c|c|c|c|c|c}
\hline Ages (years) &. & $0-4$ & $5-9$ & $10-14$ & $15-19$ & $20-24$ & $25-29$ & $30-34$ & $35-$ \\
\hline No. of cases &. & 19 & 61 & 27 & 12 & 19 & 6 & 3 & 8 \\
\hline
\end{tabular}

Clinical Observations.-All operative cases except one were acyanotic. In 58 there were no convincing cardiac symptoms, but in 78 there was a complaint of moderate breathlessness on exertion and lassitude, and in 2 activity was severely limited. There was a history of bacterial endarteritis in 12, of underdevelopment in 8 , and of systemic hypertension in 4 . The siblings of 143 patients were not affected, in 4 there was a persistent ductus, 2 were cyanotic, and in 6 the condition was undefined; 12 had endarteritis and 8 suffered from malnutrition. The diagnosis was accurate in all cases. In one case with aortopulmonary septal defect, not included in this series, the diagnosis was suspected before operation on account of the low and medial position of the murmur and thrill, and this was confirmed at thoracotomy. The most constant and valuable diagnostic sign in the uncomplicated ductus was the presence of a Gibson or "machinery murmur" indicating a left-to-right shunt in both systole and diastole (134 out of 138 operation cases-98\%), and this was accompanied by a basal systolic thrill (101 out of 138 cases-73\%).

Radiology.-Fluoroscopy revealed a normal vascular silhouette in 40 cases, a prominent pulmonary artery alone in 42 , a prominent pulmonary artery as well as left ventricular hypertrophy in 50, left ventricular hypertrophy alone in 7 , and evidence of left and right ventricular hypertrophy in 16. The differential diagnosis between enlarged hilar glands and a prominent pulmonary artery was discussed in a number of cases referred without sign or symptoms of persistent ductus.

Associated Abnormalities.-Associated abnormalities were present in 21 cases (in addition to a case complicated by a ventricular septal defect, which is mentioned below)namely, aortic aneurysm at site of ductus, 5 ; left superior vena cava, 3 ; aortic stenosis, 1 ; coarctation of the aorta, 1 ; congenital cataract, 3 ; deaf-mutism, 3 ; spastic diplegia, 2 ; hare-lip, 1 ; mental deficiency, 1 ; situs inversus viscerum, 1 . There was a history of rubella during maternal pregnancy in only eight cases.

\section{Surgery}

Operations were performed through the postero-lateral approach, usually through the fifth intercostal space, and the ductus was ligated by two No. 8 silk ligatures tied apart after carefully dissecting and retracting the pericardial reflection on to the aorta. Division and suture was practised in only five cases complicated by haemorrhage. It was not used as a routine procedure, as we were satisfied with the results of ligation. Misadventures (Table II) were largely

TABLE II.-Misadventures and Complications of Surgical Treat-

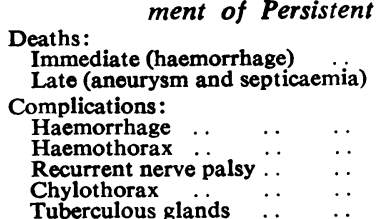

attributable to damage to the ductus or the adiacent aorta during dissection precipitating severe haemorrhage. This occurred in seven cases, of which two were fatal. In one of these there was active endarteritis in the ductus, and in the other an extreme thinness of the aorta at its junction with the ductus. In the remaining five cases injury to thin-walled congenital aneurysms projecting from the aortic end of the ductus during dissection was dealt with successfully by division and suture. In one successfully treated case complicated by haemorrhage the aorta was clamped above and below the ductus for 37 minutes without damage to the spinal cord.

A case of late aneurysm and septicaemia followed an uncomplicated second ligation for recurrence in a patient known to have a partly medically controlled endarteritis at the first operation. In both cases of haemothorax the bleeding originated from the back end of the intercostal incision and was cured by open removal of the clot. The possibility of cardiac embarrassment from overtransfusion in children is a real one and endangered several of our earlier cases. Recurrent nerve palsy followed manipulations dealing with haemorrhage from the ductus in two, and the nerve was deliberately divided in the other (the case referred to above with recurrence) to allow a safe passage to be made for ligation. The post-operative chylothorax was easily recognized, and was successfully treated by ligation of an abnormally situated thoracic duct. Dissection of a tuberculous gland in one case did not adversely affect successful ligation.

Cases complicated by intracardiac lesions have not been included in this series. However, one such case, in which pre-operative cardiac catheterization had revealed pulmonary hypertension and evidence favouring ventricular septal defect in addition to the ductus, ligation was undertaken after temporary clamping had produced no immediate ill effects. Sudden death occurred two hours later.

The presence of a shunt between the aorta and the pulmonary artery was confirmed in all cases at operation by the presence of a thrill extending into the stem of the plethoric pulmonary artery. Records of the pulmonary artery and aortic pressures were taken in 36 patients. In 22 of these the pulmonary artery pressures were within normal limits $(23 / 14 \mathrm{~mm}$. $\mathrm{Hg}$ average), but nevertheless fell slightly after ligation, there being a concurrent slight rise in aortic pressure, especially of the diastolic level. In the remaining 14 cases the pulmonary artery pressure was elevated in varying degree. As can be seen in Table III, in some there was reversion to normal (Cases 1, 2, 6, and 10), in some there was a considerable fall, but in others there was little change in pressures (Cases 3, 4, and 5).

Operative Results.-In this series there has been a mortality of about $2 \%$, with few post-operative complications and rapid recovery; late recurrences were rare. Early recanalization in uninfected cases was thought to be due to lax ligatures tied too closely together; and in the patient with endarteritis, in whom it recurred twice and who finally died from septicaemia, to be due to tissue softening associated with residual activity. Enough tissue is usually available for the ligatures to be tied apart, even in apparently fistulous communications, and there has not been recurrence even in large ducts with considerable pulmonary hypertension.

Follow-up.-Of 80 cases adequately followed up, 75 are symptom-free, 2 are improved but have causes remaining for the disability (subaortic stenosis in 1, and systemic hypertension in 1) and there have been 3 recurrences. Admittedly these figures are incomplete owing to difficulties in tracing a moving population, but it is reasonable to assume that any cases in which recurrence was suspected would be referred back for assessment.

\section{Patients Not Submitted to Surgery}

Of 17 patients on whom operation was not performed, nine were between $3 \frac{1}{2}$ and 15 years, and eight between 25 and 47 years of age.

In the children, five without cardiac embarrassment were deferred until the optimum age, in three diagnosis was uncertain, and mental deficiency without cardiac embarrassment was regarded as sufficient cause for rejection in one other. One 15-year-old boy in whom the diagnosis was indefinite when seen at his original examination two years 
TABle III.-Clinical Features and Comparative Pressures of Cases with Raised Pulmonary Artery Pressure

\begin{tabular}{|c|c|c|c|c|c|c|c|c|c|c|c|c|c|c|c|c|c|c|c|}
\hline \multirow{3}{*}{$\begin{array}{l}\text { Case } \\
\text { No. }\end{array}$} & \multirow{3}{*}{ Age } & \multirow{3}{*}{$\begin{array}{l}\text { Effort } \\
\text { Intol- } \\
\text { erance }\end{array}$} & \multirow{3}{*}{ Thrill } & \multirow{3}{*}{$\begin{array}{l}\text { Gibson } \\
\text { Murmur }\end{array}$} & \multirow{3}{*}{ B.P. } & \multirow{3}{*}{$\begin{array}{l}\text { R.V. } \\
\text { Lift }\end{array}$} & \multirow{3}{*}{$\begin{array}{l}\text { P.A. } \\
\text { Lift }\end{array}$} & \multirow{3}{*}{$\begin{array}{l}\text { Second } \\
\text { Sound }\end{array}$} & \multirow{3}{*}{ E.C.G. } & \multirow{3}{*}{$X$-ray } & \multicolumn{4}{|c|}{ P.A. Pressure } & \multicolumn{4}{|c|}{ Aortic Pressure } & \multirow{3}{*}{$\mid \begin{array}{c}\text { Clini- } \\
\text { cal } \\
\text { Result }\end{array}$} \\
\hline & & & & & & & & & & & \multicolumn{2}{|c|}{ Before } & \multicolumn{2}{|c|}{ After } & \multicolumn{2}{|c|}{ Before } & \multicolumn{2}{|c|}{ After } & \\
\hline & & & & & & & & & & & $\mathbf{S}$ & D & $\mathbf{S}$ & D & $\mathbf{S}$ & D & $\mathbf{S}$ & $\mathbf{D}$ & \\
\hline 1 & 12 & - & + & II & $118 / 54$ & - & - & N. & L.V. ++ & P.A. + & 32 & 20 & 30 & 19 & 78 & 60 & 108 & 92 & G \\
\hline 2 & 40 & ++ & + & III & $210 / 110$ & + & - & Acc. & L.V. +++ & $\begin{array}{l}\text { P.A. }+ \\
\text { L.V. }+\end{array}$ & 32 & 20 & 10 & & & & & & G \\
\hline $\begin{array}{l}3 \\
4 \\
5\end{array}$ & $\begin{array}{r}7 \\
16 \\
6\end{array}$ & $\overline{+}$ & $\overline{+}$ & $\begin{array}{l}\text { II } \\
\text { III }\end{array}$ & $\begin{array}{r}10040 \\
12565 \\
9040\end{array}$ & $\begin{array}{l}+ \\
+ \\
+\end{array}$ & $\begin{array}{l}- \\
++ \\
++\end{array}$ & $\begin{array}{l}\text { Acc. } \\
\text { Acc. } \\
\text { N. }\end{array}$ & $\begin{array}{l}\text { N. } \\
\text { N. } \\
\text { N. }\end{array}$ & $\begin{array}{l}\text { L.V. }+ \\
\text { N.A. }+\end{array}$ & $\begin{array}{l}40 \\
41 \\
42\end{array}$ & $\begin{array}{l}33 \\
23\end{array}$ & $\begin{array}{l}40 \\
38 \\
37\end{array}$ & $\begin{array}{l}28 \\
16\end{array}$ & 124 & 96 & & & $\begin{array}{l}\mathbf{G} \\
\mathbf{G} \\
\mathbf{G}\end{array}$ \\
\hline $\begin{array}{l}6 \\
7 \\
-\end{array}$ & $\begin{array}{l}11 \\
28\end{array}$ & ++ & \pm & III & $\begin{array}{l}11065 \\
150,70\end{array}$ & - & $\overline{-}$ & $\begin{array}{l}\mathrm{N} . \\
\text { Acc. }\end{array}$ & $\begin{array}{l}\text { L.V. }++++ \\
\text { L.v. }++\end{array}$ & $\begin{array}{l}\text { P.A. }+ \\
\text { P.A. }+ \\
\text { L.Y }+ \text { R }\end{array}$ & $\begin{array}{l}43 \\
44\end{array}$ & $\begin{array}{l}18 \\
30\end{array}$ & $\begin{array}{r}8 \\
35\end{array}$ & 30 & 116 & 94 & 130 & 110 & $\stackrel{G}{G}$ \\
\hline 8 & 4 & + & + & III & 100,60 & + & - & Acc. & L.V. ++ & P.A. + & 50 & 40 & 40 & 30 & 120 & 80 & 140 & 100 & G \\
\hline 9 & 7 & + & + & III & 120.60 & + & + & Acc. & N. & $\begin{array}{l}\text { P.A. }+ \\
\text { L.V. }\end{array}$ & 52 & 30 & 36 & 19 & 120 & 80 & 135 & 100 & G \\
\hline 10 & 11 & ++ & - & III & $130 / 60$ & + & - & Acc. & $\begin{array}{l}\text { L.V. }{ }^{+}+++ \\
\text {R.V. }{ }^{+}\end{array}$ & $\begin{array}{l}\text { P.A. }+ \\
\text { L.V. }+\end{array}$ & 60 & & 20 & & & & & & G \\
\hline 11 & 12 & + & + & III & $140 / 60$ & + & + & Acc. & $\begin{array}{l}\text { L.V. +R.V.+ }+ \\
\text { Part. R.B.B.B. }\end{array}$ & $\begin{array}{l}\text { P.A. }+ \\
\text { R.L.V. }+\end{array}$ & 73 & 60 & 53 & 38 & 105 & 88 & 110 & 98 & G \\
\hline 12 & 6 & - & + & III & $115 / 70$ & - & + & Acc. & L.V.t & $\begin{array}{l}\text { P.A. }+ \\
\text { L.V. }+\end{array}$ & 77 & 66 & 51 & 29 & 107 & 93 & 160 & 106 & G \\
\hline 13 & 5 & ++ & - & $\begin{array}{l}\text { Pulm. S.M. } \\
+ \text { D.M. }\end{array}$ & $90 / 50$ & - & - & Acc. & $\begin{array}{l}\text { L.V. }++^{++}++ \\
\text {R.V. }++\end{array}$ & P.A.t & 104 & 72 & 57 & 31 & 117 & 88 & 117 & 88 & G \\
\hline 14 & 3 & + & + & $\begin{array}{l}\text { Pulm.S.M. } \\
\text { +D.M. }\end{array}$ & 95,65 & - & - & Acc. & $\begin{array}{l}\text { L.V. }++++ \\
\text { R.v. }+++\end{array}$ & $\begin{array}{l}\text { P.A. }+ \\
\text { L.V. }\end{array}$ & 112 & 82 & 72 & 40 & 117 & 84 & 156 & 104 & G \\
\hline
\end{tabular}

previously, died of congestive heart failure, the post-mortem examination showing a very large persistent ductus without changes in the muscular vessels within the lungs.

In the adult cases, operation was declined by four patients and not advised in four-one of the latter cases was complicated by systemic hypertension and angina pectoris, while the remaining three were complicated by severe pulmonary hypertension. In three cases there was reversal of the shunt, with flow from right to left, at the time of examination. In two of these death occurred within twelve months and four years respectively, but the other patient remains fairly well.

The clinical history and the necropsy findings of one of these cases follow.

\section{Illustrative Case}

A married woman aged 39 was admitted to Green Lane Hospital on February 27, 1955, in congestive heart failure. She had been short of breath on exertion from the age of 11 , when a congenital heart murmur was discovered. After a transient attack of congestive heart failure following the birth of her first baby, she remained well until this recurred quite suddenly at 35 and persisted for the four years prior to admission.

On examination she was of slight build, mildly cyanosed, and in congestive heart failure; blood pressure 160/100, pulse 90. The heart was enlarged, the first sound had a slapping quality, and there was a diastolic murmur in the third intercostal space to the left of the sternum. Fluoroscopy confirmed cardiac enlargement (cardiac-thoracic ratio 65), predominantly of the right ventricle, and showed both a prominent pulmonary arc and an enlargement of the larger pulmonary arteries. By cardiac catheterization the clinical diagnosis of pulmonary hypertension was confirmed, the pulmonary arterial pressure being 150/90. The oxygen saturation of pulmonary arterial and right ventricular blood samples was identical; while a right-to-left shunt, probably from a persistent ductus, was inferred from the femoral artery oxygen saturation of $85 \%$. After a short remission she relapsed and died.

Necropsy revealed dilatation of the right atrium, massive right ventricular hypertrophy, gross dilatation of a very atheromatous pulmonary artery, and a persistent ductus, $1 \mathrm{~cm}$. in diameter, calcified on its pulmonary face. Histology showed marked narrowing of the lumina of the smaller arteries by hyperplasia of the tunica media and subendothelial thickening of the intima.
Comment.-Despite the presence of a large persistent ductus and pulmonary hypertension the patient had few symptoms until the age of 35 . Progressive endarteritic changes could be responsible for the final breakdown and the right-to-left shunt.

\section{Diagnosis}

Our experience has confirmed the observations of Gilchrist (1945) that the presence of a Gibson murmur and a thrill are the most valuable physical signs. Difficulty has been experienced in differentiating this murmur from a venous hum, an aorto-pulmonary septal defect, and ventricular septal defect with aortic incompetence. The suspicion of venous hum has been confirmed by disappearance of the murmur on local pressure at the root of the neck. A case of aorto-pulmonary septal defect was diagnosed on the signs recommended by Brown (1939), by the low position of the murmur and thrill close to the sternum, and these were confirmed at thoracotomy.

The differentiation of ventricular septal defect and aortic incompetence has been a real difficulty in two cases, and was finally arrived at by cardiac catheterization. In one, later readmitted with congestive heart failure, the clinical diagnosis of persistent ductus was confirmed at necropsy.

The absence of the Gibson murmur is quite compatible with a large flow, and has been noted especially in infants with a large persistent ductus, but is not confined to them. In some infants and young children bordering on congestive heart failure, the diagnosis may be rendered more difficult by passive congestive changes increasing the pulmonary artery pressure and reducing the shunt. The Gibson murmur is absent in another group of cases in which there is considerable elevation of the pulmonary artery pressure. In these difficult cases the presence of the ductus, the pulmonary vascular resistance, the direction of the shunt, and the volume of the flow have been found by cardiac catheterization (Table III, Cases 5, 13, and 14).

\section{Cases Complicated by Raised Pulmonary Artery Pressure}

It is generally believed that a persistent ductus arteriosusan arteriovenous fistula close to the heart-will eventually be a significant factor in left heart failure from constant overworking of this organ in response to reflex mechanisms maintaining the peripheral blood pressure (Holman, 1940).

The burden is dependent on the size of the ductus and the resistance of the pulmonary bed. Elevation of the 
pulmonary artery pressure may result purely from torrential flow through a large ductus with a low pulmonary resistance (Table III, Cases 6-10), but when the pulmonary artery pressure is elevated, cardiac catheterization studies have shown the pulmonary resistance to be usually in part responsible. Some degree of pulmonary vascular resistance at the arteriolar level is present in $25 \%$ of cases, but in the majority the effect of this can largely be relieved by interruption of the fistula. Excessive pulmonary vascular resistance with persistent ductus may be explicable as an active vasoconstriction, as suggested by Gilchrist (1945), possibly the result, as postulated by Civin and Edwards (1950), of the persistence of the foetal structure and function of the smaller pulmonary arterioles in which there is a greatly thickened arterial wall and a small lumen. Arteriolar resistance has been considered as a protective mechanism against flooding of the lungs with arterial blood under high pressure. This "compensatory" vascular resistance is apparent in some cases and not in others. The large leftto-right shunt associated with a low vascular resistance both in cases of persistent ductus and in cases of ventricular septal defect is the reason for the frequent occurrence of congestive heart failure.

In our experience with some cases characterized by elevation of the pulmonary artery pressures treated by operation, there has been less pre-operative incapacity in those cases with grossly elevated pulmonary artery pressures and increased vascular resistance than in those with a large fistula and a low vascular resistance (Table III ; compare Cases 13 and 14 with Cases 2, 6, and 10).

In 14 cases complicated by pulmonary hypertension, but all with considerable left-to-right shunt (Table III), there have been no complications following ligation of the ductus, and the clinical result was good in every case.

Holman, Gerbode, and Purdy (1953) reported the case of a patient dying at 15 years of age in whom there had been a right-to-left shunt since birth; and Smith (1954) recorded a case in which death occurred nine hours after ligation. Histological examination showed marked hypertrophy of the tunica media, endothelial thickening, and intra-arterial thrombosis in many of the diseased vessels. It is assumed that the pulmonary vascular resistance in these cases has approximated to that of the systemic circulation throughout life. The degree of shunt either way in the first instance may vary with physical circumstances, as in the second case reported by Cosh (1953), in which persistence of a greatly enlarged ductus permitted the adjustment of the upper limit of the pulmonary artery pressure to the systemic blood pressure. Ligation of a persistent ductus when there is a balance of pressure and no appreciable left-to-right shunt is a dubious procedure except possibly in babies, in whom the vascular bed might be expected to undergo its normal evolution once the abnormality is corrected for which persistence of the foetal resistance was necessary. Any reflex vasoconstriction to the pulmonary bed might be interrupted without much further hazard by autonomic denervation of the left lung at the same time.

If reversal is present, ligation has been found extremely dangerous and sudden death on the table or at an early date after operation has been experienced by many surgeons. The borderline cases in which there is some right-to-left shunt pose individual problems, and in this unit each case is considered in the light of clinical judgment and cardiac catheterization figures of the pulmonary arterial resistance and flow.

\section{Persistent Ductus in Babies and Children}

As already stated, it has been our policy to advise operation in all cases, but usually to defer operation until the age of 4 or 5 unless there was cardiac embarrassment. Half of the cases operated upon were under 11 years. In the $0-4$ age group there were 19 cases, 14 of them receiving operation treatment-in 12 because of breathlessness and restriction of activity, nutritional disturbance, and cardiac enlargement, and in two others at the parents' request. All have done well.

\section{Persistent Ductus in Adults}

Gilchrist (1945) thought that the prognosis was still open to conjecture. It is uncommon for cases of persistent ductus to present after middle life and rare after 50 years, and death from endarteritis, often masquerading as bronchopneumonia, and from congestive heart failure is generally assumed to be the reason for this. Gilchrist (1945) thought the clinical prognosis for a particular adult case to be not as serious as that indicated by necropsy findings (Keys and Shapiro, 1943), and he was willing to accept the view that patients who live to middle life were usually those with little physiological disturbance who would continue to live restricted lives with a reduced life expectancy. Medical treatment for endarteritis and the prevention of its recurrence by ligation of the ductus regardless of age has further strengthened his view.

Progressive organic obliterative changes in the pulmonary vascular bed may be expected to influence unfavourably some cases with marked elevation of the pulmonary arterial pressure and to be partly responsible for the development of the right heart failure.

Left ventricular failure is a serious hazard, usually somewhat earlier in cases with a large persistent ductus and a normal pulmonary vascular resistance, the age depending on the size of the shunt and the development of complications.

In our series of 28 adult cases submitted to operation there have been no deaths. The ductus has been noted to be fistulous, of firm consistency, and with periductal fibrosis in most cases, but no operative difficulties have been encountered and there has been neither morbidity nor recurrence. It has not been found necessary to interfere with normal delivery in one pregnant woman with this abnormality.

\section{Persistent Ductus and Endocarditis}

According to Gilchrist (1945) endarteritis is to be suspected as the basis of any persistent temperature or prolonged bronchopneumonia in a patient known to have a persistent ductus. He has found the presence of an enlarged heart and pulmonary artery together with shifting areas of bronchopneumonia on repeated $x$-ray examination (consistent with small infected pulmonary infarcts) to be helpful in making a diagnosis in the absence of a positive blood culture.

The efficacy of ligation of persistent ductus has been brilliantly demonstrated by Touroff (1940) and by Bourne et al. (1941). Vegetations at first localized to the intimal surface of the pulmonary jet end of the ductus are locked in the lesser circulation by ligation and cured. Operative intervention in the advanced cases, owing to inflammatory infiltration and softening of the ductus and to extension downwards along the ascending aorta to the aortic valve, has been shown to be one of grave hazard and dubious benefit.

Our general policy has been to make every endeavour to cure the infection with antibiotics and subsequently to ligate the ductus to prevent recurrence. Of the 12 patients with endarteritis submitted to surgery, 2 have died and 10 have been cured. Death from haemorrhage occurred in the first case, and in the second case septicaemia and ductal aneurysm followed many months after a second ligation for recanalization and active endarteritis, and the patient died of septicaemia despite full courses of antibiotic treatment. In the remaining 10 cases the infection has been controlled with antibiotics and ligation performed subsequently, at which time the tissues appeared to be normal except for residual periductal fibrosis and enlarged lymphatic nodes. 


\section{Summary}

An attempt has been made to sift some of the clinical experience from 155 consecutive cases of persistent ductus arteriosus. The results of surgery in 138 of these cases are presented briefly, together with the management of the 17 not submitted to operation. Experience is discussed and present policies are outlined in dealing with this abnormality in children and adults and when it is complicated by pulmonary hypertension and bacterial endarteritis.

We thank our colleagues in the cardio-surgical unit for permission to present this work. The operations were performed by Mr. Douglas Robb and one of us (R. N.). The help of Miss Catherine Tibbles, of the Central Medical Library, of Dr. Stephen Williams, pathologist, and of Mr. Burge, of the clinical photographic department, is acknowledged.

BIBLIOGRAPHY

Adams, Forest H. (1952). J. Pediat., 40, 42.

Bourne, G., Keele, K. D., Tubbs, O. S., and Swain, R. H. A. (1941). Lancet, $2,444$.

Brown. J. W. (1939). Congenital Heart Disease, p. 89. London.

Campbell, M., and Hudson, R. (1951). Guy's Hosp. Rep., 100, 26 Civin, W. H., and Edwards, J. E. (1950). Circulation, 2, 545.

(1951). A.M.A. Arch. Path., 51, 192

Cosh, J. A. (1953). Brit. Heart J., 15, 423.

Gilchrist, A. R. (1945). Ibid., 7, 1.

Gross, R. E., and Hubbard, J. P. (1939). J. Amer. med. Ass., 112, 729

and Longino, L. A. (1951). Circulation, 3, 125.

Holman, E. (1940). Ann. Surg., 112, 840.

Gerbode, F., and Purdy, A. (1953). J. thorac. Surg., 25, 111

tgren, H., Selzer, A., Purdy, A., Holman, E., and Gerbode, F. (1953)

Keys, A., and Shapiro, M. J. (1943). Amer. J. med. Sct., 206, 174.

Potts, W. J., Gibson, S., Smith, S., and Riker, W. L. (1949). Arch. Surg. (Chicago), 58, 612.

Record, R. G., and McKeown, T. (1953). Brit. Heart J., 15, 376.

Smith, G. (1954). Ibid., 16, 233.

Swan, H. J. C., Zapata-Diaz, J., Burchell, H. B., and Wood, E. H. (1954)

Amer. J. Med. 16, 12

Taussig, H. B. (1952). Circulation, 6, 930.

Touroff, A. S. W. (1940). J. tharac. Surg., 10, 59.

and esell, H. (1940). J Amer. med. Ass., 115, 1270

Tubbs, O. S. (1943). Proc. roy. Soc. Med., 36, 175 .

(2)

\section{VARIATION OF PLASMA ELECTROLYTE AND TOTAL PROTEIN LEVELS IN THE INDIVIDUAL}

BY

\section{J. K. FAWCETT, F.I.M.L.T. Senior Technologist}

AND

VICTOR WYNN, M.D.

Senior Lecturer in Surgery

From the Surgical Unit, St. Mary's Hospital, London, W.2

For a proper interpretation of biochemical results in disease one requires a knowledge of the variation found in the healthy population, such variation establishing a "normal range." The variations found in a healthy individual from day to day (the temporal variation) and within each day (diurnal variation) are also important. In the present study the concentrations of plasma sodium $(\mathrm{Na})$, potassium $(\mathrm{K})$, chloride $(\mathrm{Cl})$, total carbon dioxide $\left(\mathrm{T} . \mathrm{CO}_{2}\right)$, and total protein ( $\left.\mathrm{Pr}\right)$ are reported in a healthy group and in healthy individuals over a period of time. Since basal conditions cannot always be assured when taking blood for analysis, the possible effects upon these biochemical values of posture, meals, moderate exertion, and the menstrual cycle were investigated.

\section{Experimental Procedures}

Subjects.-Group A : Single samples of venous blood were taken from 25 healthy men and 25 healthy women between the ages of 20 and 35 years. Group B : Blood was taken on 10 occasions over periods of two to six months from each of four healthy young men and four healthy young women. Group C : Blood was taken from each of five young men at approximately equal intervals throughout a single day. Three were healthy ambulatory subjects and two were convalescent patients lying in bed. Normal diets of known composition were eaten, and intake and output balances for the electrolytes and water throughout the day were calculated. Group D : Blood was taken twice a week from two young women during two consecutive menstrual cycles and from a third during one menstrual cycle.

Methods.-Venous blood was taken without stasis into a heparinized syringe and centrifuged under paraffin without delay. $0.04 \mathrm{ml}$. of heparin (5,000 units per ml.) was used for $10 \mathrm{ml}$. of blood. Most specimens, except under Group C, were taken between 10 a.m. and noon, and not less than one hour after meals or vigorous exertion. In studying the women in groups $\mathrm{A}$ and $\mathrm{B}$, samples were taken so that all stages of the menstrual cycle were equally represented. Analytical methods were as follows : $\mathrm{Na}$ and $\mathrm{K}$, using a laboratory-made flame photometer employing coal-gas and compressed air, a light filter system, and an external standard; $\mathrm{Cl}$, Sanderson's (1952) potentiometric method; T.CO ${ }_{2}$ content, Van Slyke and Neill's (1924) manometric method; Pr, a semi-micro Kjeldahl procedure (Fawcett, 1954). Analyses were performed at least in duplicate. The coefficient of variation (due to analytical error) was found to be as follows: $\mathrm{Na}, 0.5 \% ; \mathrm{K}, 1.0 \% ; \mathrm{Cl}, \mathbf{0 . 6 \%} ; \mathrm{T} . \mathrm{CO}_{2}, 0.8 \% ; \mathrm{Pr}$ $1.0 \%$; and for duplicate analyses the figures would be : $\mathrm{Na}, 0.4 \% ; \mathrm{K}, 0.7 \% ; \mathrm{Cl}, 0.4 \%$; T. $\mathrm{CO}_{2}, 0.6 \% ; \mathrm{Pr}, 0.7 \%$.

\section{Results}

The electrolyte and protein results are expressed in terms of mean values $(m)$ and standard deviations $(\sigma)$. This is valid because the results from the healthy subjects in group A are each distributed in the form of a Gaussian (normal) curve. Wootton and King (1953) observed a similar distribution except in the case of $K$, in which it was lognormal. Josephson and Dahlberg (1952), however, found a Gaussian distribution of $\mathbf{K}$ in health. The plasma electrolyte and protein results in groups $\mathrm{B}, \mathrm{C}$, and $\mathrm{D}$ are also distributed in Gaussian curves about the individual's mean level.

Table I reports the mean values, standard deviations, and $95 \%$ ranges of $\mathrm{Na}, \mathrm{K}, \mathrm{Cl}, \mathrm{T} . \mathrm{CO}_{2}$, and $\mathrm{Pr}$ for 25 healthy young men and 25 healthy young women. The standard

TABLE I.-Plasma Electrolyte Concentrations ( $\mathrm{mEq} / \mathrm{l}$.) and Total Protein Concentrations $(\mathrm{g} . / 100 \mathrm{ml}$. $)$ in 25 Healthy Young Men and 25 Healthy Young Women

\begin{tabular}{|c|c|c|c|c|c|}
\hline & $\mathrm{Na}$ & $\mathbf{K}$ & $\mathrm{Cl}$ & T.CO & Pr \\
\hline $\begin{array}{l}\text { Mean }(m) \text { for } \\
\text { men } . \dot{~} \\
\text { Standard devia- } \\
\text { tion }(\sigma) \text { for men } \\
95 \% \text { range for } \\
\text { men }(m \pm 2 \sigma)\end{array}$ & $\begin{array}{c}141 \cdot 7 \\
1 \cdot 0 \\
139 \cdot 7-143 \cdot 7\end{array}$ & $\begin{array}{c}4 \cdot 11 \\
0 \cdot 27 \\
3 \cdot 57-4 \cdot 65\end{array}$ & $\begin{array}{c}101.8 \\
1.4 \\
99.0-104.6\end{array}$ & $\begin{array}{c}29 \cdot 5 \\
1.6 \\
26 \cdot 3-32 \cdot 7\end{array}$ & $\begin{array}{c}7 \cdot 33 \\
0.25 \\
6 \cdot 83-7 \cdot 83 \\
\end{array}$ \\
\hline $\begin{array}{cr}\text { Mean }(m) & \text { for } \\
\text { women } & \text {. } \\
\text { Standard devia- } \\
\text { tion }(\sigma) & \text { for } \\
\text { women } & \ldots \\
95 \% \text { range } & \text { for } \\
\text { women }(m \pm 2 \sigma)\end{array}$ & $\begin{array}{c}140 \cdot 5 \\
1.7 \\
137 \cdot 1-143 \cdot 9\end{array}$ & $\begin{array}{c}4 \cdot 12 \\
0.32 \\
3 \cdot 48-4 \cdot 76\end{array}$ & $\begin{array}{c}103 \cdot 0 \\
1 \cdot 2 \\
100 \cdot 6-105 \cdot 4\end{array}$ & $\begin{array}{c}28 \cdot 1 \\
1 \cdot 6 \\
24 \cdot 9-31 \cdot 3\end{array}$ & $\begin{array}{r}7 \cdot 30 \\
0.32 \\
6 \cdot 66-7 \cdot 94 \\
\end{array}$ \\
\hline $\begin{array}{l}\text { Value of } t \text { for sex } \\
\text { difference } \\
\text { Probability level } \\
\text { for sex differ- } \\
\text { ence }\end{array}$ & $\begin{array}{c}3.1 \\
0.001<\mathrm{P} \\
<0.01\end{array}$ & $\begin{array}{c}0.12 \\
0 \cdot 1<P\end{array}$ & $\begin{array}{c}0.001<\mathrm{P} \\
<0.01\end{array}$ & $\begin{array}{c}3.2 \\
0.001<P \\
<0.01\end{array}$ & $\begin{array}{r}0.29 \\
0.1<P\end{array}$ \\
\hline
\end{tabular}

deviations and ranges are less than those generally reported -for example, Wootton, King, and Maclean Smith (1951), Josephson and Dahlberg (1952), and Wootton and King (1953). This may be attributed to our narrower age group and to the different chemical methods employed. The following differences between the sexes, all highly significant statistically, were detected. In women $\mathrm{Na}$ is $1.2 \mathrm{mEq} / 1$. lower, $\mathrm{Cl}$ is $1.2 \mathrm{mEq} / \mathrm{l}$. higher, and T.CO${ }_{2}$ is $1.4 \mathrm{mEq} / 1$. lower than in men. There is no difference of $\mathrm{K}$ or $\mathrm{Pr}$ between the sexes. The standard deviation for $\mathrm{Na}$ is greater in women than in men. 